\title{
Financing for climate change
}

\section{Citation}

Cooper, Richard N. 2012. “Financing for Climate Change." Energy Economics 34 (November): S29-S33. doi:10.1016/j.eneco.2012.08.040.

\section{Published Version}

doi:10.1016/j.eneco.2012.08.040

\section{Permanent link}

http://nrs.harvard.edu/urn-3:HUL.InstRepos:13578515

\section{Terms of Use}

This article was downloaded from Harvard University's DASH repository, and is made available under the terms and conditions applicable to Open Access Policy Articles, as set forth at http:// nrs.harvard.edu/urn-3:HUL.InstRepos:dash.current.terms-of-use\#OAP

\section{Share Your Story}

The Harvard community has made this article openly available.

Please share how this access benefits you. Submit a story.

Accessibility 
June 2012

Revised

\title{
Financing for Climate Change
}

\author{
Richard N. Cooper \\ Harvard University
}

The Copenhagen Accord of December 2009 pledged that the rich countries would provide $\$ 100$ billion a year by 2020 to contribute to abatement of greenhouse gas emissions in developing countries and to facilitate adaptation in the most vulnerable countries to such climate change as will occur as a result of increases in carbon dioxide concentration in the atmosphere that have already occurred, and will increase at least in the next few decades. "This funding will come from a variety of sources, public and private, bilateral and multilateral" and is to be "new and additional." This paper addresses the question how best to finance abatement of greenhouse gas (GHG) emissions worldwide, with the objective of slowing and eventually perhaps even stopping changes in the world's climate that are expected to be generated by emissions of carbon dioxide from consumption of fossil fuels and changes in land use (e.g. cutting of forests) as well as by other known greenhouse gases.

An underlying assumption of this paper is that climate change cannot be significantly slowed through actions by the rich countries alone, such as that called for by the Kyoto Protocol of 1997, which in any case expires in 2012. Current projections, based on demonstrated success in many developing countries in growing income and modernizing their economies, suggest that by 2020 carbon dioxide emissions from fossil fuel consumption alone (leaving aside other sources of emissions) in developing countries will exceed worldwide greenhouse gas emissions in 1990, the base year of the Kyoto Protocol. In other words, rich countries could notionally reduce their emissions to zero by 2020 (which certainly will not happen in reality) and the developing countries alone would be emitting on the global scale of 1990. Put simply, slowing climate change significantly cannot occur without the active participation of at least the largest emitters among the developing countries; the likelihood that even drastic action by the rich countries alone will solve the problem is minimal.

That dismal reality was grudgingly recognized by the Copenhagen Accord and reaffirmed the following year at Cancun. Developing countries as a group then riposted that at least the rich countries should pay for the necessary mitigation, or at least a significant portion of it; hence the pledge of $\$ 100$ billion. 
How is it to be financed? To address this question Secretary General Ban Ki-moon of the United Nations constituted a 20-member high-level advisory group (all but three of whom were sitting government officials or officials of international organizations), co-chaired by Meles Zenawi and Jens Stoltenberg, prime ministers of Ethiopia and Norway respectively. It reported in November 2010, and made 6-7 suggestions (approximate expected net flows to developing countries in parentheses):

1) Allocate to developing countries 10 percent of revenues in rich countries from a $\$ 20-25$ a ton tax on carbon dioxide-equivalent emissions, or equivalent revenues from auctioning emission permits (\$30 billion);

2) Impose an emission tax on international transportation (but insulate developing countries from its incidence), and allocate 25-50 percent of revenues to developing countries ( $\$ 10$ billion);

3) Redeploy to developing countries domestic fossil fuel subsidies now given by rich countries or, alternatively, impose a financial transactions tax (up to $\$ 10$ billion);

4) Expect increased private investment flows of $\$ 100-200$ billion stimulated by the carbon tax, of which $\$ 10-20$ billion could be reckoned to be net flows to developing countries;

5) Expect increased carbon market flows of $\$ 30-50$, of which around $\$ 10$ billion would be net transfers to developing countries;

6) Increase lending by multilateral development banks by $\$ 30-40$ billion, of which $\$ 11$ billion is reckoned to be net flows.

These suggestions produce $\$ 80-90$ billion in net flows to developing countries, associated with

much larger gross flows. The Advisory Group also expects that direct budgetary contributions from rich countries would play a role. It concludes that meeting the Copenhagen target is "challenging but feasible."

One puzzling feature of this report is its emphasis on grant equivalent transfers to developing countries. It is well established in the literature on foreign assistance to calculate the grant equivalent, since the detailed terms of such assistance (maturity, interest rate, etc.) vary significantly, and a metric must be found to compare the assistance by different donors. But the Copenhagen Accord does not mention foreign aid, or foreign assistance. It speaks of "resources" and of "funding," as though the challenge was to find sources of funds to make the additional investments in developing countries required to mitigate greenhouse gas emissions. The emphasis of the Advisory Group's report on grant equivalents (apparently with some difference of opinion within the Group) suggests that it was seeking yet another channel of foreign assistance to developing countries, a constant theme of developing countries in international forums since the 1960s. There is a significant difference between the need to find funds to make upfront investments in any activity, with social returns to be reaped later; and the desire to make resource transfers to poor countries, augmenting their incomes (some of which might be allocated to investment). The Copenhagen Accord seems to focus on the former, although it is admittedly unclear; the Advisory Group's Report focuses on the latter. 
Grants to countries have some well-known problems. First, unless they are solely devoted to purchases of imported capital equipment that would not otherwise be purchased, they distort prices domestically and they inhibit exports through the so-called Dutch disease effect, by which prices of nontradable domestic goods and services are bid up, thus discouraging production for export. A grant equivalent of $\$ 100$ billion would amount to 0.7 percent of projected GDP for non-OECD countries (less China and Russia) in 2020, and over three percent of exports from those countries, so it would be quantitatively significant. Second, large foreign grants are an invitation to non-productive rent-seeking behavior in the recipient countries at best, and outright corruption in many countries. The Advisory Group observes that "The credibility of...countries....will be greatly increased...if there is confidence that these resources will be spent wisely...and produce results." This is a correct but disappointingly weak statement on the need to assure that Copenhagen funds are spent productively for the purposes for which they were intended.

The proposals in the UN Report have been given further analysis and specificity in a report to the G20 Finance Ministers prepared by several international organizations (World Bank et al., 2011). This report focuses properly on sources of finance for investments in mitigation and adaptation. It provides "purely illustrative scenarios" of such sources under six broad headings (following the UN report) that cumulatively total $\$ 186-413$ billion by 2020 - well in excess of the Copenhagen/Cancun commitments. But it also points to present difficulties in economic conditions and growing fiscal pressures in most developed countries, making many new financial commitments difficult (see Houser and Selfe, 2011, for problems in the United States). This places a premium on those scenarios that involve either cutting expenditures - such as the subsidies that encourage production and consumption of fossil fuels - or raising revenues, such as a charge on greenhouse gas emissions or auctioning permits for such emissions.

Like the Copenhagen commitment, the UN Advisory Group and the World Bank efforts focus on the financing side; they do not address whether the funds could be productively used to attain the desired objectives. This logical gap is filled by William Cline (2011), who addresses the potential demand for funds for mitigation in developing countries. Cline specifies a "business-as-usual" emission scenario for the world's 25 largest emitters to 2050. He then adopts the notional Copenhagen target that greenhouse gases (carbon dioxide and its equivalents in other gases) should not exceed 450 parts per million by 2050, with the objective of limiting warming to 2 degrees centigrade. He postulates that emissions to achieve this aggregate target should be equalized around the world on a per capita basis, at 1.43 tons per person by 2050, necessary in his view to gain the cooperation of developing countries (a condition which is questionable if indeed climate change is as undesirable for developing countries as is implicit in the analysis). Within this overall framework he calculates emission trajectories for each of his 25 countries. Drawing on cost functions from several sources, he estimates the costs of attaining these trajectories, both with and without cross-border trading of emission rights. His overall conclusion is that the annual cost will be economically manageable, rising from .22-1.33 percent of gross world product in 2030, depending on the cost assumptions used, to 1.15-2.92 percent in 2050. Cross-border sales of emission rights reduce the total cost, but by surprisingly little. He translates the desired trajectory into investment requirements, to be followed by considerable returns in energy saving, and concludes that 
developing countries (less China) could productively use $\$ 41$ billion annually for abatement by 2020, and China alone could use $\$ 53$ billion, but probably does not require external financing. Adaptation costs might add an additional $\$ 40$ billion, placing the total of $\$ 81$ billion somewhat below the $\$ 100$ billion target.

Both the UN report and Cline's analysis neglect a central problem in dealing with global mitigation of greenhouse gas emissions. It will not be feasible for governments to cover all of the appropriate mitigation costs from their budgets, which everywhere are strained thanks to the financial crisis and recession of 2008-2009. The major portion of costs must be imposed on emitting firms, who in turn will try to pass them on to customers as an additional cost of doing business. But if some jurisdictions in the world do not impose such costs on their firms, they will gain a potential competitive advantage with respect to firms located in jurisdictions which do impose such costs, e.g. through a GHG emissions charge or through a requirement for emission permits which must be purchased. Over time, and other conditions permitting, firms will relocate from jurisdictions imposing such costs to jurisdictions which do not impose such costs. This will not only be politically intolerable in the costimposing jurisdictions; it will also weaken the effectiveness of the entire arrangement, since GHG emissions will have been relocated geographically to countries where enforcement is weak and corruption is endeminc. Any scheme that does not address this issue squarely is bound to fail. To a first approximation, and possibly with some allowance for small differences in timing, the cost of GHG mitigation must be the same for all competing firms, wherever they are located. The Copenhagen Accord does not address this sensitive issue. And the UN Advisory Group also ignores it, implicitly assuming that firms in developing countries will be relieved of the costs of mitigating their emissions, since those costs are to be borne by developed countries through resource transfers. Cline also does not address this issue. Yet it is crucial to finding a viable solution.

This issue is not merely hypothetical. We have seen during the past two decades a major relocation of the world's steel industry, to China. Driven by a large domestic demand for steel, Chinese steel production capacity was greatly increased with the help of cheap loans from state-owned banks. Extensive and not-well-coordinated growth in capacity led to excess capacity, aggravated by the 2009 slowdown in world demand, and China has now become a significant exporter of steel - a major energyusing industry. Some European countries have protected their steel industries in the context of a carbon emission trading scheme by allocating free emission permits far in excess of expected need for them, thus in effect using the emission trading scheme to subsidize that (and some other) industry, since the excess permits can be sold in the trading market (Cooper, 2010). Other countries, including the United States, imposed duties on some Chinese steel products.

A special case of this general phenomenon would arise if developing countries used government-to-government transfers to subsidize or otherwise protect state-owned enterprises, which often are in competition with private enterprises from other countries in the world market and indeed within domestic markets; but the concern extends beyond trade to putting foreign enterprises wishing to invest in emerging markets at a competitive disadvantage, e.g. with respect to building facilities and infrastructure, and even with respect to investment in research and development. 
In short, the world trading system is seriously at risk in the face of a poorly designed system for global mitigation of greenhouse gases (Frankel, 2010). Countries will want to protect their industries from "unfair" competition from countries whose firms do not incur costs for their greenhouse gas emissions. Estimating the appropriate import duties will be difficult because of the diverse sources of electricity and the need to attribute emissions to particular products (Houser, 2008). This difficulty will inevitably translate into arbitrary levels of countervailing duties, and ones that probably will err on the high side.

Of course, such duties would deal only with exports, not with domestic sales in competition with imports; and a significant fraction of the increased costs would fall on non-tradable goods and services, such as electricity for lighting of buildings.

There is in fact a straight-forward solution to this joint problem of creating incentives to reduce greenhouse gas emissions without distorting international trade and investment. It is for every country to impose the same charge on greenhouse gas emissions, particularly carbon dioxide derived from use of fossil fuels. As a practical matter, not all countries need be included initially; but all those with a reasonably well-developed industrial base, which either does or could in the near future include firms with significant emissions, would need to be included to inhibit regulatory arbitrage. In practice, this would certainly include a number of countries that are not covered in Annex B of the Kyoto Protocol, above all China but also Chile, Mexico, South Korea, Turkey (all members of the OECD), Argentina, Brazil, India, Indonesia, Iran, Pakistan, Malaysia, Thailand, South Africa, and no doubt several others.

The charge should be uniform, although a brief transition period of no more than five years might be allowed to developing countries. Revenues would accrue to the governments levying the charges, and they would be free to use the revenues in any way that did not undermine the purpose of the arrangement, viz. to discourage the emission of greenhouse gases. Ministers of finance everywhere would welcome a new, internationally sanctioned source of revenue. Most governments around the world today are strapped for revenue, the major exception perhaps being some countries which rely heavily on the export of oil or gas for their government revenues. Under current circumstances no doubt many countries would devote at least a portion of new revenues to the reduction of budget deficits and the need to borrow to cover such deficits. Some revenues could be devoted to reducing other taxes, which would appeal especially in the United States. Some revenues could be used to cushion those firms or households which were hurt exceptionally by the introduction of the charge (as proposed by Metcalf). Some could be devoted to research and development into ways to find substitute sources for fossil fuels ("renewables," interpreted broadly) or to conserve energy without cutting back productive activity. And some could be allocated to helping the most vulnerable countries to adapt to such climate change as occurs. The central point is that no significantly emitting firm, anywhere, public or private, should be protected from the incentive to reduce its emissions.

Some will claim that such an arrangement would be inequitable, in that the carbon charge would fall on rich and poor alike. And so it would, although of course those who consume more carbonintensive goods would pay proportionately more. An analogy might be helpful. Today everyone pays the full going price of scarce mineral resources, such as oil or copper. The world does not discriminate 
between rich and poor in consumption of these scarce resources; we help the poor, when we help them at all, in other ways, through the tax systems or provision of public services. The debate on climate change presupposes that we now realize that the atmosphere is also a scarce resource, at least when it comes to disposing of greenhouse gases in it. Like the consumption of copper, its capacity is reduced by additional emissions, whether by rich or by poor. We should therefore charge everyone for its use, to discourage its use as a medium of disposal by everyone.

A central, and legitimate, concern of many developing countries is that actions to mitigate climate change should not compromise their path to development, or reduce their rate of economic growth. It is often assumed, without analysis, that raising the effective price of energy (in the form of fossil fuels) to productive firms will slow the rate of economic growth. This assumption could be correct in some circumstances, but in general it will not be correct. One can identify at least four channels through which permanent increases in prices of fossil fuels might affect the rate of growth: energy as a direct input to production; use of the revenue from the carbon charge; impact on the cost of capital goods and hence potentially on the rate of investment; and impact on international competitiveness and hence potentially on export growth.

\section{Economic Growth}

Energy is a key input to many aspects of modern economies, including traditional activities such as agriculture. Surely raising the price of energy will discourage production? However, for a variety of reasons energy is used very inefficiently in China, India, and indeed many developing countries, relative to actual practice in rich countries. Thus the possibility exists to produce the same output with a lower input of energy. Sometimes this change simply requires an adequate incentive, such as higher energy prices. Sometimes it requires an incentive plus new knowledge about better practice. Sometimes it requires an incentive plus new investment in more energy-efficient structures or equipment. And of course new investment requires funding. So investments may be diverted from other destinations to energy saving, and on that account lower growth. It is noteworthy, however, that many energy-saving investments would yield handsome rates of return if energy prices were higher. Moreover, developing 
countries must make large investments in power generation and distribution to support their growth aspirations, and to the extent energy efficiency can be improved, such investment could be reduced, releasing both labor and capital to be used elsewhere in the economy, thus contributing to growth. On one estimate, for example, China must spend an average of $\$ 67$ billion a year over the period 20012030, over two percent of GDP, to satisfy its growing requirements for electricity (IEA, 2003, p.353). Even saving ten percent of this would leave $\$ 7$ billion a year for investment in other activities.

As noted above, a carbon charge will raise revenue. How those revenues are used can influence the rate of growth. If they are used to replace growth-inhibiting taxes on capital, the net impact might be to accelerate growth. Thus the simulations by Ho and Jorgenson $(2007, p .357)$ find that GDP is actually higher with a carbon charge, revenues used to reduce other taxes, than it would be without the charge - i.e., growth has been (modestly) stimulated.

If, as is more likely in many developing countries, the revenues are used to finance expenditures, the impact on growth will depend on the magnitude and the growth-enhancing effects of those expenditures. Expenditures on transport infrastructure will presumably contribute to growth, as would expenditures on under-funded agricultural research and dissemination, or on education. Expenditures on enlarging or modernizing military forces, in contrast, would not contribute much to growth. Thus each government would have substantial discretion over how much the carbon charge could be directed toward enhancement of growth.

A third channel of influence on growth would be through the cost of capital goods, hence the real investment that could be undertaken for any given nominal level of investment spending. Raising the cost of capital goods, other things equal, will reduce growth. Raising the price of energy would increase the cost of those capital goods that are high in direct energy content, such as construction steel and cement. On the other hand, many capital goods are not energy intensive. Moreover, the impact of 
energy price increases on capital goods prices would be mitigated to the extent, per the first point above, that as a result of the carbon charge producers increased significantly the efficiency with which they used energy. It is even conceivable that capital goods prices would fall, as efficiency improvements outweighed increased energy prices. Furthermore, in a sufficiently long run technical change can be expected, as in the past, to reduce the prices of many capital goods. There has been no secular decline over recent decades in the real return to private capital in rich countries, those on the technological frontier, as capital-saving technical change has compensated on average for the declining returns that might have been expected to flow from the tremendous accumulation of capital that has occurred during the past half century.

Finally, higher energy prices, other things being equal, will increase the relative price of energyintensive products, hence reduce the competitiveness of those products on world markets. A serious loss of competitiveness could, through a variety of channels, reduce economic growth.

Here the international environment in which any country imposes a carbon charge comes into play. Under the proposal here, all countries would impose a similar carbon charge, so the competitiveness channel would be neutralized for all countries. Energy-intensive products would see a rise in relative price everywhere, so their consumption would be discouraged, and countries that specialized in the export of such products would experience an impact on their exports. But no country would gain directly in competitiveness product-by-product at the expense of other countries, except insofar as they were superior at reducing the energy content of their exports, or at substituting other energy sources for carbon-emitting sources of energy.

A charge on carbon emissions can be expected, over time, to stimulate new research and development on methods to reduce the carbon content of energy. It is difficult to predict the 
development and impact of future technology, but in the end this may provide a significant positive impetus to growth.

\section{Revenues}

The revenues that can be expected to accrue from a charge on greenhouse gas emissions will of course depend both on the magnitude of the charge and on the response to the charge. The US Energy Information Administration has projected global carbon dioxide emissions from burning fossil fuels in 2020, reported in Table 1, based on assumptions regarding regional economic growth until then, sectoral demands for energy, and the fuel mix that will be used to satisfy these demands (EIA 2011). Let us assume that a carbon charge of $\$ 25$ a ton of $\mathrm{CO} 2$ has been introduced worldwide by 2020 . (This is similar in nominal terms to the price of $\mathrm{CO} 2$ on the European trading system in 2008 before the financial crisis and subsequent recession; Australia in 2012 introduced a charge of $A \$ 23$ a ton, scheduled to rise by 2.5 percent a year for several years.) Table 1 reports the revenues this would generate before allowing for behavioral change in response to the charge, thus representing an upper limit to the revenues that might be generated, in US dollars and as a share of gross domestic product used by EIA in making the projections of energy demands. It can be seen there that $\$ 880$ billion might be earned worldwide. China would raise the greatest amount of revenue, at $\$ 252$ billion, reflecting its large emissions of $\mathrm{CO} 2$, followed by the United States at $\$ 145$ billion and OECD Europe at $\$ 102$ billion. $\$ 332$ billion would be raised in all member countries of the Organization for Economic Cooperation and Development (OECD), which included mainly Annex B countries but also Chile, Mexico, South Korea, and Turkey. Annex B countries in the non-OECD category include Russia and Ukraine.

Table 1

Emissions and Revenues in 2020 
CO2 Emissions

(billion metric tons)

USA

OECD Europe

Japan

Total OECD

China

India

Brazil

Russia

Total non-OECD

World

35.2

4.1

1.1

13.3

10.1

2.1

0.6

1.6

22
Revenues

(\$ billion)

(percent of GDP)

145

0.8

102.5

0.5

27.5

0.5

332.5

0.7

252.5

2.6

52.5

2.2

15

0.8

40

3.3

550

2.2

880

1.2

Source: calculated from EIA 2011; China's GDP augmented by 30 percent to allow for 2005-2011 currency appreciation; see text.

The revenues would amount to 1.2 percent of gross world product (GWP) in that year, somewhat less for the OECD countries and about two percent for the non-OECD countries. At 3.3 percent, Russia registers the highest percentage of the countries listed, followed by China at 2.6 percent. Revenues of course do not measure the impact of the economic cost of limiting CO2 emissions; these in general will be lower than the revenues raised. 
The EIA projections use of prices and exchange rates of 2005, adjusted here for appreciation of the Chinese yuan by 30 percent between 2005 and 2011. Further appreciation can be expected during the decade of the 2010s, so the share of China's revenues would probably be below two percent of GDP in 2020. There will also probably be some real appreciation of the Indian rupee and the Brazilian real during this period, along with some other currencies in countries that are developing rapidly, following a well-established pattern. Finally, prices will have risen everywhere above their level of 2005. Thus gross world product (measured in 2020 dollars) will be higher than that assumed by the EIA, and revenues from the carbon charge will be a correspondingly lower percentage of GWP and of non-OECD GDP. Thus if world inflation averages 3 percent between 2005 (EIA's price year) and 2020, GWP will be 55 percent higher in nominal terms, and revenues would be 0.8 percent of 2020 GWP. An annual two percent inflation in OECD countries and four percent in non-OECD countries would reduce those percentages to 0.5 percent and 1.2 percent respectively. Alternatively, the carbon charge could be raised to $\$ 39$ a ton of CO2, which would restore the percentages in Table 1 after allowing for 3 percent annual inflation.

Behavioral responses would depend among other things on how much advance notice economic decision-makers had of the imposition of the carbon charge, on the opportunities they had for reducing CO2-emitting fossil fuels, and on the costs of those opportunities. One estimate of the magnitude of the behavioral response can be calculated from Cline $(40,60)$, who estimates that the United States and Europe must reduce their emissions by 17 percent by 2020 to achieve the emission reduction implicit in the Copenhagen consensus. This will lead to a shadow price per ton of $\mathrm{CO} 2$ of $\$ 19$ a ton in 2020 in the United States and $\$ 26$ a ton in Europe (in prices of 2020, assuming inflation of 3 percent a year from $2005)$, and expected to rise thereafter to $\$ 121$ and $\$ 159$, respectively, by 2030 (in nominal dollars). Because Cline allows developing countries some delay in their required actions, their price of $\mathrm{CO} 2$ is zero in 2020, rising to $\$ 119$ in 2030 for China, for instance. The decline of 17 percent can be taken to provide a rough indictor to the expected early behavioral response following pre-announced introduction of a carbon charge on the order of $\$ 20-25$. So revenues in 2020 would be somewhat lower than those presented in Table 1, but not a lot lower.

The IEA (2009) suggests that an additional \$10.5 trillion must be invested globally in the energy sector over the two decades 2010-2030 to get to a viable path for stabilizing atmospheric $\mathrm{CO} 2$ concentration at $450 \mathrm{ppm}$, the same as Cline's target. However, $\$ 8.6$ trillion will be recouped in energy 
saving, resulting in a net economic abatement cost of $\$ 1.9$ trillion over this period. From these figures it might be inferred that the ratio of initial investment to ultimate abatement cost would be roughly five to one. But Cline points out that this inference would be incorrect. The investment enlarges the capital stock, and the services from the enlarged capital stock (after allowance for depreciation) persist year after year. So after a few years of initial investment the on-going annual incremental investment costs are likely to be smaller, not larger, than the abatement costs.

\section{Conclusion}

The paper argues that $\mathrm{CO} 2$ and other greenhouse gas emissions should be treated as a cost of doing business everywhere, just as purchasing copper or other material inputs into production is a cost of doing business. Everyone should pay the world price. That would signal to everyone there is a social cost to emitting greenhouse gases. Prices signal scarcity value. Otherwise foreign trade and investment will be seriously distorted in ways that not only will undermine the world trading system but also would weaken the effort to limit $\mathrm{CO} 2$ concentrations in the atmosphere by shifting emitting activities to jurisdictions where emissions were not a cost of doing business.

On the calculations of William Cline, an initial charge of around \$25 per emitted ton of CO2 in 2020 , rising over time, would be adequate to cover the investment costs of a level of abatement required by 2050 to converge on an atmospheric $\mathrm{CO} 2$ concentration level of 450 parts per million, thought (admittedly with much uncertainty) to be necessary to limit warming of the earth's surface to 2 degrees centigrade. If such a charge were imposed everywhere, it would not distort trade and investment. And it need not reduce economic growth, of special interest to developing countries, although investment requiring much steel, cement, and other high-energy using investment goods would be somewhat more expensive.

Where does that leave the pledge for funding of $\$ 100$ billion a year by rich to poor countries? It should certainly not be used for abatement at the level of the firm, for the reasons given. It could certainly be used for adaptation in vulnerable countries to such climate change as takes place, although on Cline's estimates it would be much more than required for that purpose alone. It could also be used to undertake research and development into energy conservation and non-emitting sources of energy. One such activity would be construction of pilot plants for carbon capture and storage (CCS), success at which would permit more extensive use of coal, the main current and prospective source of $\mathrm{CO} 2$ emissions. Our knowledge of what CCS is technically and economically feasible on a commercial scale is seriously inadequate; we could be experimenting with new coal plants in developing countries, since capture is likely to be much less expensive if planned into the beginning of a new project than through retrofitting existing plants. Indeed the funds could be used for anything that did not distort the relative costs and prices of goods produced and sold on the international market.

\section{References}


Cline, William R., Carbon Abatement Costs and Climate Change Finance, Washington: Peterson Institute for International Economics, 2011.

Cooper, Richard N., Europe's Emissions Trading System, Washington: US Climate Task Force, 2010.

Frankel, Jeffrey, "Global Environment and Trade Policy," in Joseph E. Aldy and Robert N. Stavins, eds., Post-Kyoto International Climate Policy, Cambridge University Press, 2010.

Ho, Mun S., and Dale W. Jorgenson, "Policies to Control Air Pollution Damages," in Mun S. Ho and Chris Nielsen, eds., Clearing the Air: the Health and Economic Damages of Air Pollution in China, Cambridge, MA: MIT Press, 2007.

Houser, Trevor, et al., Leveling the Carbon Playing Field: International Competition and US Climate Policy Design, Washington: Peterson Institute for International Economics, 2008.

Houser, Trevor, and Jason Selfe, Delivering on US Climate Finanace Commitments, Working Paper 11-19, Peterson Institute for International Economics, 2011.

Jacoby, Henry D., el al., "Sharing the Burden of GHG Reductions," in Joseph E. Aldy and Robert N. Stavins, eds., Post-Kyoto International Climate Policy: Implementing Architectures for Agreement, Cambridge University Press, 2010.

Metcalf, Gilbert E., A Proposal for a US Carbon-Tax Swap: An Equitable Tax Reform to Address Global Climate Change, Washington: Brookings Institution, 2007.

International Energy Agency, World Energy Investment Outlook, Paris: OECD, 2003.

International Energy Agency, World Energy Outlook 2009, Paris: OECD, 2009.

United Nations, Report of the Secretary-General's High-level Advisory Group on Climate Change Financing, New York, 2010.

World Bank, International Monetary Fund, and Organization for Economic Cooperation and Development, Mobilizing Climate Finance, A paper prepared at the request of G20 Finance Ministers, Washington: World Bank, 2011. 
'The $\$ 100$ billion in 2020 is markedly lower than some other figures that have been mentioned. For instance Jacoby et al., based on a target trajectory of maximum 450 ppm CO2-equivalent, produce simulations on the MIT energy-climate model that produce required transfers to developing countries in 2020 of over $\$ 400$ billion if they are to be compensated in full for the costs of mitigating climate change. This figure, however, includes compensation for adverse movement in the terms of trade of developing countries, the main component of which is a decline in oil prices for OPEC exporters, something that will, to put it mildly, be hard to sell to legislatures in oilimporting countries. 